\title{
Introduction to the Digital and Cybernized Services and Digitalization and Cybernation of Services Minitrack
}

\author{
Tilo Böhmann \\ Universität Hamburg \\ tilo.boehmann@uni-hamburg.de
}

\author{
Jan Marco Leimeister \\ University of St. Gallen \\ janmarco.leimeister@unisg.ch
}

\author{
Tuure Tuunanen \\ University of Jyväskylä \\ tuure@tuunanen.fi
}

The purpose of the minitrack is to attract research on the innovation, design, development, management, and use of digital services and the digitalization of services. The key drivers in this area of research are the multiplying technological opportunities for digital services, such as ubiquitous connectivity, artificial intelligence, wearable devices, cyber-physical systems, Internet of Things (IoT), virtual/augmented reality, and so on. The minitrack provides a discussion forum for researchers interested theoretical and practical problems related to such services [1-4].

In a broad sense, digital services can be defined as systems that enable value co-creation and limit value co-destruction through the development and implementation of ICT enabled processes that integrate system value propositions with customer value drivers [5-7]. Such services meld the worlds of bits and atoms and promise to transform the transportation, energy, and other sectors like the media industries before them. They draw on different technologies such as sensors, real-time analytics of data, augmented and virtual realities, computer hardware, software, and human and system actors. Such technologies form a service platform where different actors [] assemble the service together, in situ, as argued by Grönroos [9]. As a result, the embedded systems of today and the Internet-of-things of tomorrow are the precursors for the upcoming era of cybernized services [10]. Examples of such services are, e.g., biomedical and healthcare systems such as telerobotic surgery, (semi)autonomous vehicles and intelligent highways, augmented human capabilities with body net sensors and virtual reality, and intelligent machines.

Furthermore, there are substantial opportunities for ICT and digitalization driven service innovation in industrial and business-to-business settings. These opportunities exist particularly in manufacturing in which innovation activities increase the digitization of products and production processes. We see that the global awareness of the power of the manufacturing industry will be linked to horizontal cyber- physical systems that enable value co-creation and co-destruction in the networked business environment. The cyber-aspects of such systems are ICT infrastructure, computer hardware, software, and different kind of sensors and actors. These components turn cyber-physical systems into platforms for designing and operating service. The data on products and processes gained through networked cybernized services and the ability to act on this data through control systems and actors enables novel ways of cocreating service in industrial contexts.

This emerging area of research raises interesting questions [11]. For example, traditional development approaches focus on improving the efficiency and effectiveness of organizational processes. The design of such services may, however, require an emphasis on the sociopsychological aspects, such as the value-in-use and user/consumer/co-creator experiences. Digital services create novel ways of engaging customers and other actors in service ecosystems, raising the question of effective patterns of such digital actor engagement [5-8]. Moreover, digital services facilitate data-driven and analytics-based service design and development, particularly if the service is linked to the physical world through sensors and/or people's interactions. The shift of consumer and enterprise personnel from users to co-creators and co-destructors of value, calls for a significant re-appraisal of our current design and development approaches.

This year we received seven submissions, of which three were accepted to the minitrack with an acceptance rate of $43 \%$. This year all of the accepted papers dealt some aspects of value cocreation or co-destruction. The articles are summarized in below.

Exploring Archetypes of Value Co-Destructive Privacy Practices by Christian Kurtz, Pascal Vogel, and Martin Semmann. The paper looks at personal data as a critical resource to tailor digital services to the context of use and the preferences of individual users. The authors argue that services have the characteristic that users and 
providers no longer interact in a dyadic relationship but rather in service systems cocreating value. Here, actors can provoke adverse effects that result from misaligned or destructive behavior. Building on a multi-case analysis of information privacy violations reported in the news, the authors report seven archetypes of value co- destruction. These archetypes enable an understanding of underlying conceptions and mechanisms of actor arrangements that inhibit the holistic consideration of normative values such as information privacy in digital services.

Harnessing Digital Services for Co-creating Sustainability Value in the Retail Servicescapes by Juuli Lumivalo, Kati Clements, and EmmaStina Hannuksela. The paper argues that while the importance of sustainable consumption is well acknowledged and consumers increasingly demand sustainable alternatives, the consumption of environmentally strenuous products also continues to grow. Technological solutions have been discussed for addressing this misalignment between consumers' attitudes and behavior. The authors use the service-dominant logic lens to investigate how digital services may be harnessed to drive the co-creation of sustainability value in the retail industry. The findings indicate that understanding and harnessing consumers' personal sustainability goals may be the key to designing digital services that help mitigate the impacts of consumption through value cocreation. We propose a preliminary framework for sustainability value co-creation and codestruction in the retail industry and discuss its implications.

Factors Enabling and Hindering Value CoCreation in Continuous Service Development: A Systematic Literature Review by Jenny Elo, Juuli Lintula, Tuure Tuunanen, and Markus Salo. The paper presents a systematic literature review investigating the factors that enable and hinder value co-creation in organizations' continuous service development processes. Employing the lens of service-dominant (S-D) logic, the authors classify the identified factors into three interrelated dimensions: institutions, resources, and service exchange. The findings report organizations' efforts to support the emergence of positive rather than negative value outcomes when implementing continuous practices in their service development.

\section{References}

[1] I. R. Bardhan, H. Demirkan, P. Kannan, R. J. Kauffman, and R. Sougstad, "An interdisciplinary perspective on IT services management and service science," Journal of Management Information Systems, vol. 26, no. 4, pp. 13-64, 2010.

[2] K. N. Lemon and M. H. Huang, "IT-Related Service: A Multidisciplinary Perspective," Journal of Service Research, vol. 14, no. 3, p. 251, 2011.

[3] R. F. Lusch and S. Nambisan, "Service Innovation: A Service-Dominant Logic Perspective," MIS Quarterly, vol. 39, no. 1, pp. 155-175, 2015.

[4] C. Peters et al., "Emerging digital frontiers for service innovation," Communications of the Association for Information Systems, vol. 39, no. 1, 2016.

[5] J. Lintula, T. Tuunanen, and M. Salo, "Conceptualizing the Value Co-Destruction Process for Service Systems: Literature Review and Synthesis," in Proceedings of the 50th Hawaii International Conference on System Sciences, 2017.

[6] T. Tuunanen, M. Myers, and H. Cassab, "A Conceptual Framework for Consumer Information Systems Development," Pacific Asia Journal of the Association for Information Systems, vol. 2, no. 1, pp. 47-66, 2010.

[7] T. Vartiainen and T. Tuunanen, "Value cocreation and co-destruction in an is artifact: Contradictions of geocaching," in $S$ Proceedings of 49th Hawaii International Conference on System Sciences, 2016.

[8] K. Storbacka, R. J. Brodie, T. Böhmann, P. P. Maglio, and S. Nenonen, "Actor engagement as a microfoundation for value co-creation," Journal of Business Research, vol. 69, no. 8, pp. 3008-3017, 2016.

[9] C. Grönroos, "Adopting a service logic for marketing," Marketing Theory, vol. 6, no. 3, pp. 317-333, 2006.

[10] T. Tuunanen, E. Kazan, M. Salo, R.-L. Leskelä, and S. Gupta, "From Digitalization to Cybernization," Scandinavian Journal of Information Systems, vol. 31, no. 2, p. 3, 2019.

[11] M. Barrett, E. Davidson, J. Prabhu, and S. L. Vargo, "Service Innovation in the Digital Age: Key Contributions and Future Directions," MIS Quarterly, vol. 39, no. 1, pp. 135-154, 2015. 